\title{
ОСОБЕННОСТИ ОЗНАКОМЛЕНИЯ ДЕТЕЙ С ЮРТОЙ В ДОШКОЛЬНОЙ ОБРАЗОВАТЕЛЬНОЙ ОРГАНИЗАЦИИ
}

\section{FEATURES OF FAMILIARIZING CHILDREN WITH THE YURT IN A PRESCHOOL EDUCATIONAL ORGANIZATION}

\section{B. Salchak}

Ch. Ondar

Summary: In this article discusses the peculiarities of the familiarizing children with the yurt in a preschool educational organization, the cognitive development of the children through a yurt, the attitude to the yurt of the children themselves. Forms of work with the children to involve children with the culture of the people through the equipping of a developing object-spatial environment. Creation of the imitation models of yurts in the conditions of a preschool educational organization. The definition of the concept «Yurt» is given.

Keywords: ethnocultural activity, yurt, interior decoration of a yurt, cognitive development of a child, preschool educational organization.
Салчак Байлак Валерьевна

К.п.н., ФГБОУ ВО «ТувинскИй государственный университет», г. Кызыл

Ондар Чечена Момужаевна

К.п.н., доцент, ФГБОУ ВО «Тувинский государственный университет», г. Кызыл chechena.o@mail.ru

Аннотация: В статье рассматриваются особенности ознакомления детей с юртой в дошкольной образовательной организации, познавательное развитие детей посредством юрты, отношение к юрте самих детей. Формы работы с детьми по приобщению детей к культуре народа через оснащение развивающей предметно-пространственной среды. Создание имитационных макетов юрт в условиях дошкольной образовательной организации. Дается определение понятия «Юрта».

Ключевые слова: этнокультурная деятельность, юрта, внутреннее убранство юрты, познавательное развитие ребенка, дошкольное образовательная организация.
B долоном возрасте у человека происходит наиболее интенсивное развитие личности, в основе которого, в т.ч. лежит и приобщение к культурному национальному наследию; в этот период начинают развиваться те чувства, черты характера, которые незримо связывают ребенка (будущего взрослого человека) с духовным богатством своего народа и освоением национальной культуры, определяется средой, конкретными условиями проживания, знанием семейным укладом, предметным окружением. Корни этой связи выражаются: в языке народа, его песнях, играх, впечатлениях, получаемых от природы родного края, в деталях быта, нравах и обычаях людей.

Федеральный государственный образовательный стандарт дошкольного образования РФ направлен на решение принципов дошкольного образования, одним из которых является учет этнокультурной ситуации развития детей, приобщение детей к социокультурным нормам, традициям семьи, общества и государства [5], что осуществляется через знакомство с национально-культурными особенностями региона, в данном случае - Pеспублика Тыва.

В Республике Тыва по сравнению с другими регионами России, сохранен уклад жизни; определенная часть населения в районах региона до сих пор проживает в войлочных юртах на чабанских стоянках. Но, например, в городской среде дети слабо имеют представления о юрте - традиционном жилище тувинского народа, слабо владеют информацией о внутреннем убранстве и назначении предметов быта, а также название частей юрты; поэтому оптимально считать проявление наибольшего интереса при изучении юрты будет у дошкольников; в дошкольной образовательной организации детей учат находить сходство и отличие внешнего вида строения и его внутреннего убранства от других видов жилья человека. В каждой дошкольной образовательной организации (ДОО) региона созданы уголки приобщения к национальной культуре, оснащение и содержание которого зависит от воспитателя; но также есть ДОО, которые на территории участка имеют юрты, как маленького размера для детей, так и настоящего большого размера.

Юрта для тувинца - это целый мир.

Юрта (также устар. кибитка) - переносное каркасное жилище с войлочным покрытием у тюркских и монгольских кочевников[6].

Юрта - это жилище кочевых народов, которую считают экологически безопасным и чистым, ее деревянный легкий каркас можно свернуть за считанные минуты, погрузить на лошадей и отправиться на перекочевку к местам зимнего или летнего выпаса скота [2]. За многовековую историю существования юрты, ее внутреннее и внешнее устройство обросло множеством устоявшихся традиций и ритуалов; каждая вещь стояла строго на сво- 
ем месте и имела важное ритуальное значение.

Ч.М. Ондар отмечает, что сакрализация юрты осуществляется с помощью ряда предметов, размещение которых на положенном месте и точное исполнение относящихся к ним предписаний превращают юрту в освоенное пространство, противостоящее прочему миру; это следующие предметы: очаг (ожук); дверь и порог (эжик); дымовое отверстие (хараача), расположенное в верхней части юрты; шест (багана), придающее юрте устойчивость; алтарь с изображениями буддийских божеств, священными книгами и прочими ритуальными предметами (бурган ширээзи), который полагалось иметь каждой семье [3].

Порядок расположения предметов домашнего обихода в юрте таков: в правой стороне, ближе к двери, находится большой деревянный шкаф для посуды (үлгүүр); далее у стены должна быть кровать (орун) хозяев, на которой не положено сидеть посторонним, даже почетным гостям. Перед кроватью должны находиться хозяйка, ее дочери и близкие родственницы. Напротив входа, на почетном месте - дөр стоят несколько деревянных орнаментированных сундуков (anmapa), где хранятся самые дорогие вещи и на этом месте должны сидеть хозяин и почетные гости. В левой стороне находятся сложенные в кучу шубы, одеяла (чүък); далее следовали сумки (барба), предназначенные для хранения сухих продуктов (зерна). Обстановка юрты заканчивались деревянной вешалкой (чыргыраа), куда вешали узды, аркан, седло. И возле двери стоял сосуд для закваски молока (доскаар) (рис. 1).

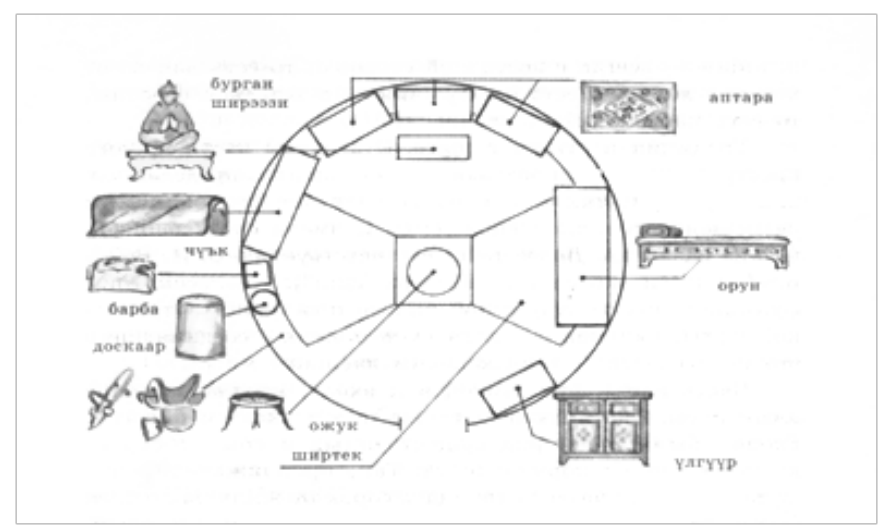

Рис. 1. Жилое пространство юрты

Б.В. Салчак было предложено конструирование образовательной среды за счет создания и обогащения предметно-пространственных характеристик целостных дизайн-проектов этнокультурной направленности, были предложены обучающие центры в виде мини-юрты или уголка юрты, в которых проводятся занятия [4, с.16], развлечения под руководством хозяйки юрты; они представляют собой: полстены (өгнүң ханазы - сборно-раздвижное основание юрты, которое состоит из 2-3 секций решеток, соединенных друг с другом по диагональным осям планки, что позволяет растягивать или стягивать их), длинные цветные ленты прикрепленные к дымовому отверстию юрты (хараача) вместо деревянных жердей (ынаалар); вдоль складных решеток обставлены предметами, имитирующими реальную утварь: шкафчик для посуды (улгүүрге), кровать (орун-дөжек), национальные сундуки (anmapa), сумки (барба), посередине очаг (ожук), также по возможности ковры (ширтек), сосуд для питья (көгээржик), пиалы (аяк), корыто (деспи) и другое.

Если проанализировать уголки юрты в дошкольных образовательных организациях города Кызыла Республики Тыва, то можно увидеть, что в некоторых ДОО при создании уголков юрты придерживаются правил расположения предметов домашнего обихода. Например, в МАДОУ комбинированного вида №31 города Кызыла все предметы юрты максимально приближены к настоящим по оформлению, соответствуют расположению и соразмерны росту детей, состоят: из очага (ожук), шкафа для кухонной посуды (үлгүүр), деревянной кровати (орун), двух деревянных орнаментированных сундуков (anmaра), сумок (барба), также имеются самодельные куклы в национальных тувинских костюмах (рис. 2).

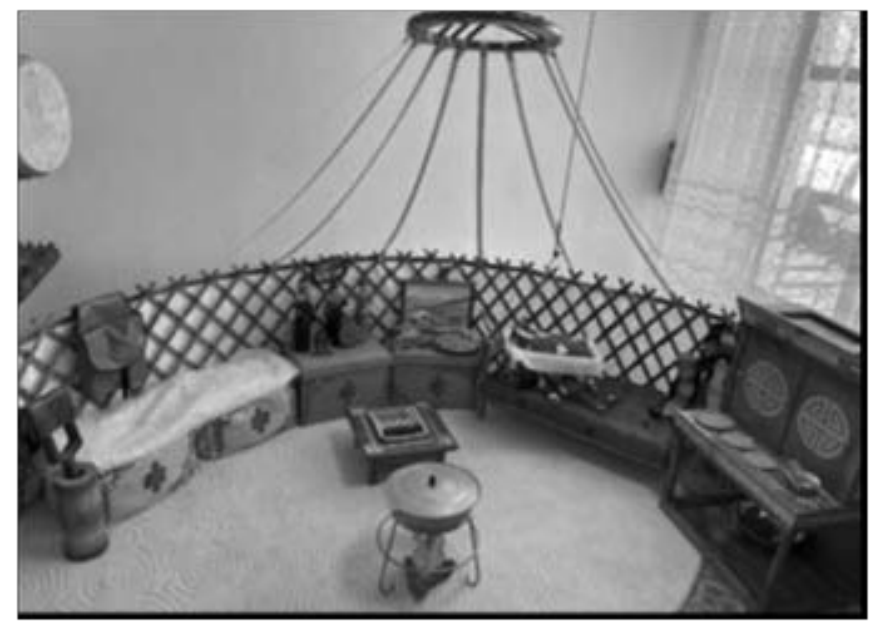

Рис. 2. Уголок юрты в МАДОУ комбинированного вида №31

В то же время есть ДОО, которые не придают значения внутреннему убранству юрты и предметы расположены не по порядку. Например, в МБДОУ Детский сад № 7 (рис. За) и МБДОУ комбинированного вида «Детский сад №28» (рис. 36) видно, что кровать находится с левой стороны и большого размера, т.е. не соразмерно с другими предметами. В МАДОУ Детский сад №1 «Золотой ключик» (рис. Зв) и МАДОУ детский сад №34 «Светлячок» комбинированного вида (рис. Зг) порядок расположения предметов соблюдены, но в то же время расположение внутри юрты не соответствует, т.е. напротив двери на почетном месте должны быть расположены сундуки, а в этих ДОО - кровати. 
a)

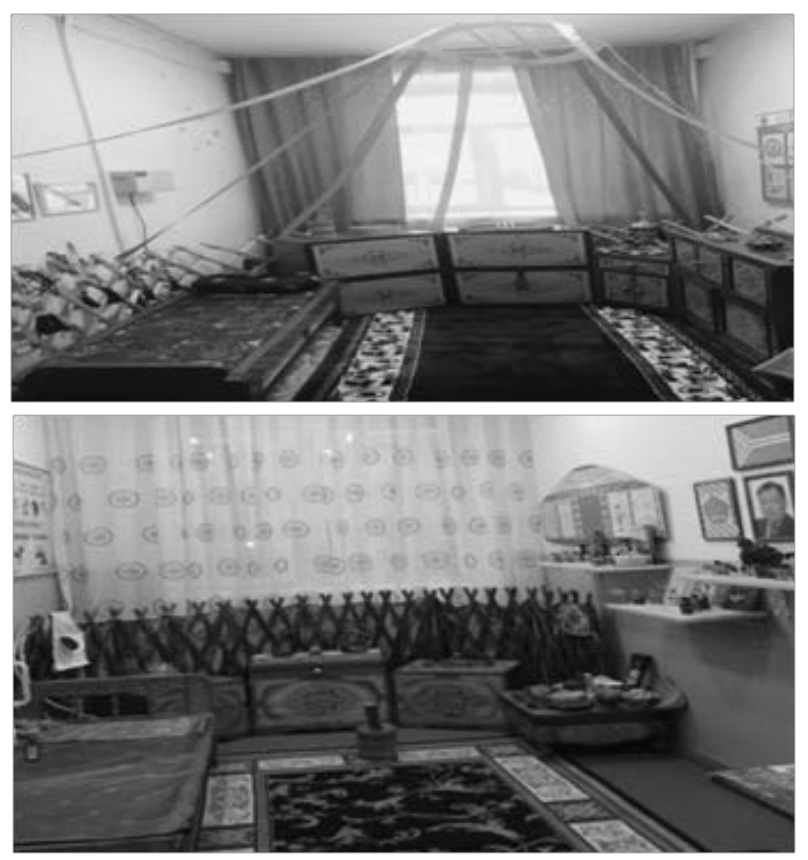

B)
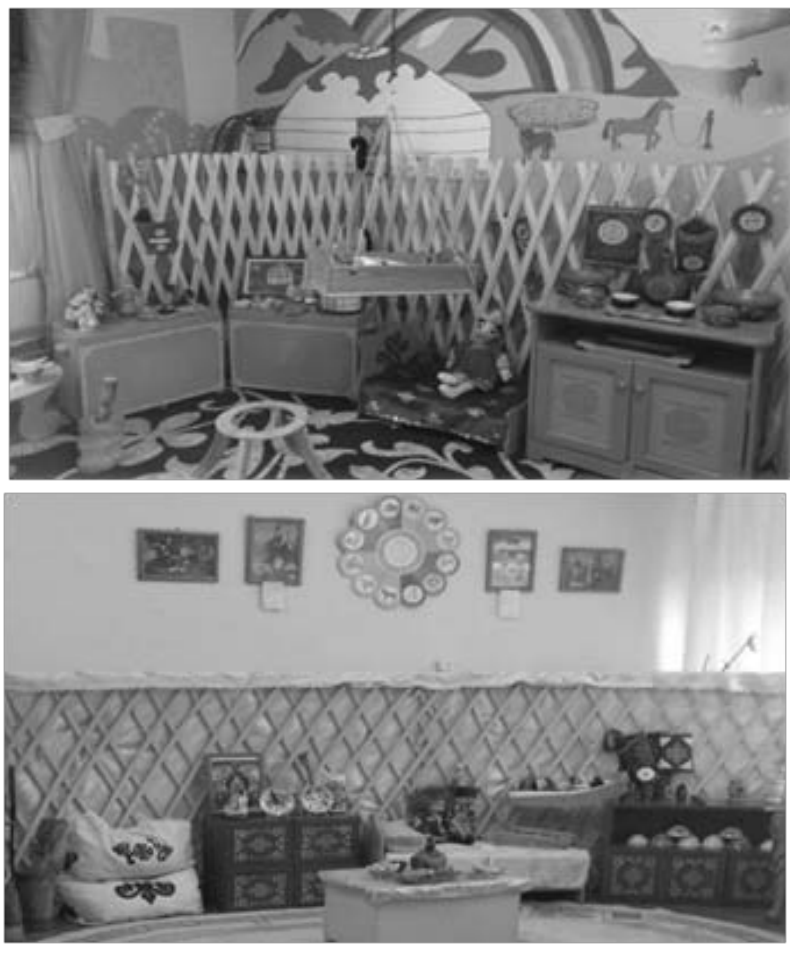

Рис. 3 а, б, в, г. Уголок юрты

Важно не забывать, что внутреннее убранство юрты строго регламентировано и отвечает представлениям кочевников о гармонии межличностных и общественных отношений; например, каждому члену семьи, каждому гостю в юрте соответствует свое, определенное место, предписанное древними правилами, поэтому при создании уголка юрты не должны нарушаться правила.

4.М. Ондар особое внимание уделяет созданию интерьера «юрта» в групповой комнате дошкольной образовательной организации, что дает возможность ребенку поиграть «во взрослую жизнь» в исторической обстановке; при знакомстве с юртой у детей обогащается словарный запас [3]. Дети начинают различать составляющую деревянную часть каркаса юрты и употреблять слова (рис. 4а): өгнүң ханазы (сборно-раздвижное основание юрты, которое состоит из отдельных секций решеток, соединенных друг с другом, образуя круговую стену юрты); ынаалар (длинные деревянные жерди, в своем множестве образующие крышу юрты); хараача (самая верхняя часть юрты, служащая для прохождения дыма от очага, для закрепления в нем верхних концов ынаалар); эжик (дверь, который состоит из косяка и деревянной створки), в то время, когда заменяли их словами крыша, стены, потолок. Помимо этого, дети знакомятся с некоторыми названиями войлочной части юрты, состоящая из следующих частей (рис. 46): дээвиир - өгнүң кырының шывыы (два войлочных покрытия юрты, где задняя часть побольше, чем передняя); адаккы - хана даштындан өгну долгандыр шывар кидис, (войлочное покрытие вокруг решетчатой стены юрты); өреге - кыжын болгаш соок дүнелерде хараачаны дуй тыртып алыр кидис (войлок, с помощью которого покрывают зимой или в холодные ночи верхнюю часть (хараача) юрты); кур - өгнүң адаккыларының даштындан өгнү долгандыр куржап алыр сарлык дугүнден азы аът челинден эшкеш, тудуштур сырып каан чептер (войлочные пояса из шерсти яка или гривы коня для укрепления юрты изнутри и снаружи прикрепленные к косяку двери); ширтек - ак хой, хураган дугунден салган энчектен сырып тургаш кылган чадыг (войлок сотканный из белой шерсти овцы для настила в юрте).

a)

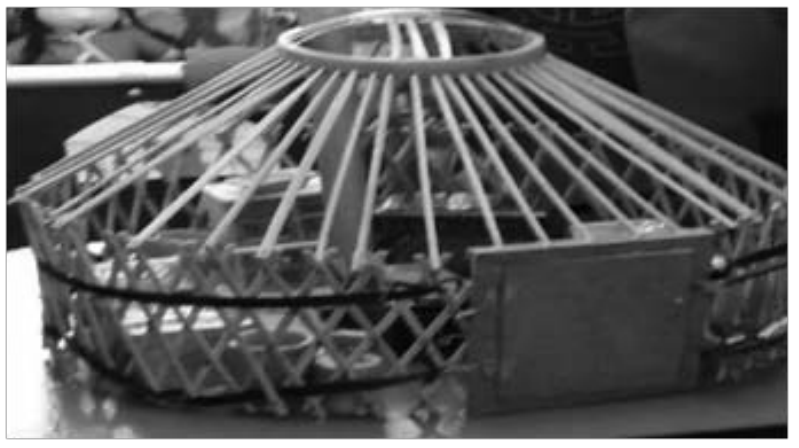

б)

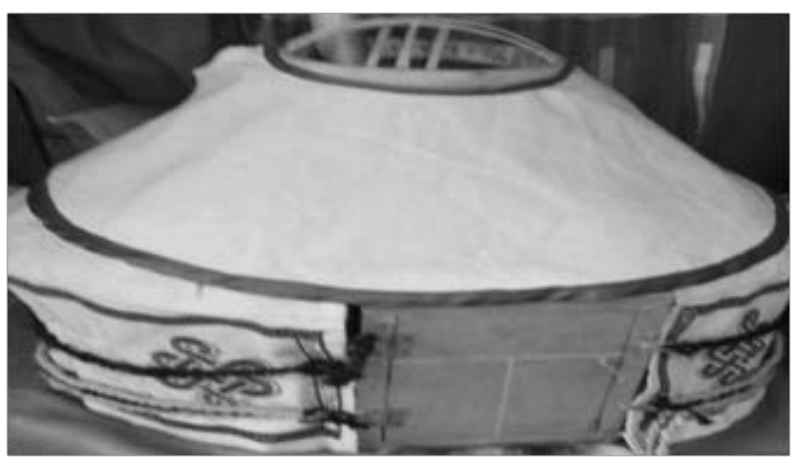

Рис. 4 а, б. Макет юрты 
Для знакомства с предметами быта и их расположением можно использовать макет юрты; интерьер «юрта» позволяет организовать сюжетно-ролевые игры и театрализованную деятельность на этнографическом материале.

Hanpuмep, педагог расставляет на столе макет юрты и просит определить, что стоит рядом с кроватью, что слева от сундука; между какими предметами находится очаг. Затем перемещает предметы так, чтобы они стояли друг за другом, и спрашивает: «Что теперь стоит, перед каким предметом, правильно ли стоит? За каким предметом должен стоять другой предмет? Перед чем стоит сундук?» и т.д. Полезно проводить игры в лабиринты, предлагать детям определять направление движения с помощью стрелок-указателей, перемещаться в пространстве в соответствии с планом маршрута; с помощью простейших схем дети должны определить правильное место рассаживания детей внутри юрты, правильно дойти до своего места, которое они должны занять внутри юрты, когда в нем другие взрослые и т.п.; дети не только «двигаются» в соответствии со стрелками-указателями, описывают путь героев, но и с помощью воспитателя моделируют, создают собственные планы маршрутов.

Проводимый авторами эксперимент определил критерии уровней знаний о юрте:

- высокий: ребенок владеет дифференцированными представлениями о внутреннем убранстве юрты; о материалах, используемых в строительстве юрты и изготовлении предметов быта; правил поведения, с легкостью отвечает на вопросы заданий, дополняет своими наблюдениями;

- средний: ребенок владеет первоначальными представлениями о внутреннем убранстве юрты; о материалах, используемых в строительстве юрты и изготовлении предметов быта; ответы не полны; ошибочно имеет представления о правилах этикета в юрте; справляется с предложенными заданиями, присутствуют 2-3 ошибки;

- низкий: ребенок владеет отдельными неаргументированными, первоначальными представлениями о внутреннем убранстве юрты; о материалах, используемых в строительстве юрты и изготовлении предметов быта; ответы не полные и неаргументированные; не справляется с заданиями, либо отказывается от выполнения предложенных заданий.

Эксперимент проводился для сравнения в городском и сельском ДОО в старшей группе, были предложены следующие задания:

- Задание 1. Беседа в форме игры «Закончи предложение».

- цель: выявить первоначальные знания о юрте.

- вопросы:
1. Как называется жилище тувинского народа?... юрma.

2. У дома четыре угла, а у юрты... нет углов.

3. Как называется верхнее отверстие юрты?... хараяча.

4. Место, где разводят огонь называется... очаг.

5. Самое почетное место в юрте, это ... дор.

6. Левая сторона при входе считается... мужской, а правая... женской.

7. Что такое войлок?

- 3адание 2. Выбрать предметы быта юрты на картинках: сундук, кресло, шкаф для посуды, диван, стул, полка, кровать, стол, очаг, колыбель, лестница,

- задание 3. Назвать части юрты по картинке.

Анализ результатов: на вопрос «Как называется жилище тувинского народа?» городские дети ответили словом «дом», некоторые дети отказывались, у сельских детей в ответах прозвучали слова «дом на земле», юрта. На логический вопрос «У дома четыре угла, а у юрты..., большинство детей сказали - «нет ничего», дополнили юрта круглая. Не удалось получить ответ и на вопрос «Верхнее отверстие юрты называется...» городские и сельские дети предложили следующие ответы: «труба», «дырка», «окно». Интересными были ответы детей на вопрос «Место, где разводят огонь называется...» озвучены были слова «печка», «костер». Вопрос «Самое почетное место в юрте ...» почему то, большинство назвали диван, кресло, многие не знали ответа, пожимая плечо. Мы не получили ответы и на следующий вопрос «Левая сторона при входе считается..., а правая...». На вопрос «Что такое «войлок»?» дети отвечали «наверно что-то тувинское» или пожимали плечами, также были ответы «Я такого не видел и не встречал». При выполнении задания 2 дети называли 1-2 предмета с общим наименованием: это кровать, это стол, это шкаф, а когда показали картинку, сельские дети четко и быстро называли все предметы быта юрты. Задание 3. «Назвать части юрты» тоже не принесло результатов; сельские дети путались в названиях.

После получения анализа результатов авторы исследования перешли к процессу ознакомления с юртой, целью которой являлось: формирование устойчивого познавательного интереса старших дошкольников по изучению юрты - традиционного жилища тувинского народа. В первую очередь, была организована предметно-развивающая среда, для того, чтобы интерес был устойчивым, назначили хозяйкой юрты педагога дополнительного образования, т.е. учителя тувинского языка в дошкольной организации. В вечернее время предлагалось детям художественное творчество, работа с красками: «украсим аптара», «украсим сыртык», «украсим көгээржик», материалы: краски, образцы, картинки с разными простыми орнаментами (рис.5). 

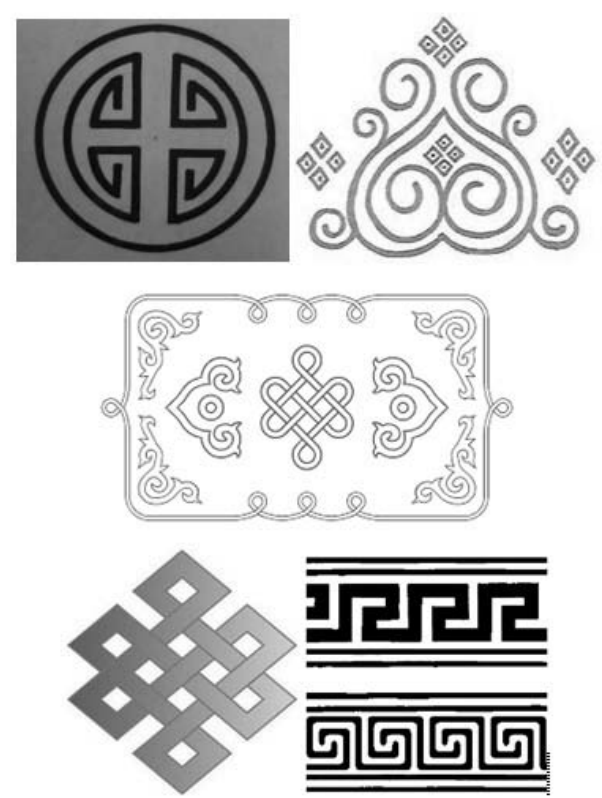

Рис. 5. Работа с красками - разные простые орнаменты

Далее, был разработан цикл тематических занятий. Одно занятие повторялось дважды, но с элементом новизны; были проведены мастер классы по изготовлению и шитью «туткууштар» (прихватки), валяние шерсти, вязание теплых носко, это работа носила волонтерский характер, созданные руками педагогов и родителей из- делия дарились многодетным семьям или в качестве подарка во время празднования «Шагаа» в ДОО самому пожилому гостю.

Авторы исследования считают, что развитие познавательного интереса детей дошкольного возраста посредством юрты будет успешным при выполнении следующих условий:

- создание пространственной предметно-развивающей среды, способствующей познавательному интересу детей дошкольного возраста;

- проведение систематических циклов занятий по ознакомлению с юртой;

- применение наглядных дидактических материалов о юрте - жилище тувинского народа с ее характерными составляющимися.

Таким образом, отношение к юрте, ее использование, места в ней для каждого члена семьи и гостей в зависимости от их пола, возраста и социальной роли, а также размещения отдельных предметов утвари - все это достаточно строго регламентировалось сложившимися традициями, было хорошим средством формирования нравственных начал ребенка, формирования человека как личности; в пределах юрты располагается весь мир людей, в ней заключается время и пространство, хозяйство и богатство, отношение в семье, этика и права.

ЛИТЕРАТУРА

1. Байыр-оол М.С. Юрта в тувинской традиционной культуре // Новые исследования Тувы. - №2. - 2013. - С. 67-70.

2. Вайнштейн С.И. Мир кочевников центра Азии. - М.: Наука, 1991. - 296 с.

3. Ондар Ч.М. Этнокультурные традиции тувинского народа в формировании пространственно-временных представлений у детей старшего дошкольного возраста // Гуманитарный вектор. - 2009. - № 3 (19). - С. 41-47.

4. Салчак Б.В. Конструирование образовательной среды воспитания национального самосознания детей дошкольного возраста (на примере Республика Тыва) // Гуманитарный вектор. - 2009. -№4. - С.16. URL: https://cyberleninka.ru/article/n/konstruirovanie-obrazovatelnoy-sredy-vospitaniya-natsionalnogosamosoznaniya-detey-doshkolnogo-vozrasta-na-primere-respubliki-tyva/viewer (дата обращения: 17.04.2021).

5. Федеральный государственный образовательный стандарт дошкольного образования. - М.: Центр педагогического образования, 2014. - 52 с.

6. Юрта [Электронный ресурс]. - Режим доступа: https://ru.wikipedia.org/wiki/\%D0\%AE\%D1\%80\%D1\%82\%D0\%B0 (дата 0бращения: 22.04.2021).

(c) Салчак Байлак Валерьевна, Ондар Чечена Момужаевна (chechena.o@mail.ru).

Журнал «Современная наука: актуальные проблемы теории и практики» 